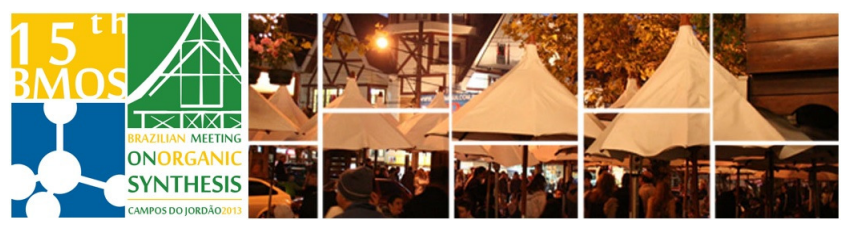

\title{
New Emissive Rhodamine Dimer Probes for Mercury Detection in Solution, Gas Phase and Cellulose Supported Devices
}

\section{Cristina Núñez, ${ }^{a, b^{*}}$ Emilia Bértolo, ${ }^{a}$ Alcindo A. Dos Santos, ${ }^{c}$ Mario Diniz, ${ }^{b}$ José Luis Capelo, ${ }^{b}$ Carlos Lodeiro ${ }^{b}$}

\author{
${ }^{a}$ Ecology Research Group, Department of Geographical and Life Sciences, Canterbury Christ Church \\ University, CT1 1Q U, Canterbury, United Kingdom. \\ ${ }^{b}$ BIOSCOPE Group, REQUIMTE-CQFB, Chemistry Department, Faculty of Science and Technology, \\ University NOVA of Lisbon, Caparica Campus, 2829-516, Portugal \\ 'Instituto de Química, Universidade de São Paulo, Av. Prof. LineuPrestes, 748, CxP. 26077, 05508-000 \\ São Paulo, Brazil \\ *e-mail:cristina.nunez@fct.unl.pt
}

Keywords: rhodamine, mercury, cellulose

\section{INTRODUCTION}

The extreme toxicity of mercury and its derivatives results from its high affinity for thiol groups in proteins and enzymes, leading to the dysfunction of cells and consequently causing health problems. Therefore, the detection of mercury becomes increasingly important in the aspect of both environment and human health.

\section{RESULTS AND DISCUSSION}

Following our research interest on the development of new colorimetric and fluorescent chemosensors $^{1}$ and with the knowledge that mercury ion presents a strong thiophilic affinity, we report here two new rhodamine-based chemosensors 1 and 2 (Scheme 1). ${ }^{2}$
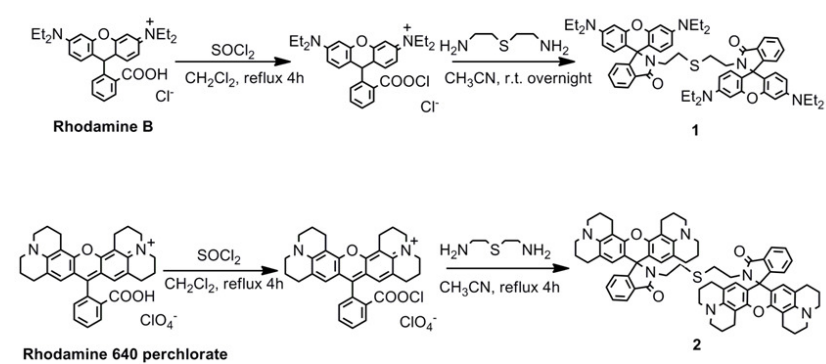

Scheme 1. Synthetic route of compounds 1 and 2.

Surprisingly, the low solubility of probes $\mathbf{1}$ and $\mathbf{2}$ in water presents an advantage thinking in future real applications. Chemosensors 1 and 2 could be supported in low cost and simply cellulose discs to determine $\mathrm{Hg}^{2+}$ in aqueous solution $(\mathrm{pH}=6.9-7.2)$.

The color scale observed between pink and violet in just 5 seconds could be related with the different concentrations of this pollutant metal ion in aqueous solution. This method could be really useful for the development of portable and convenient in-the-field detection of $\mathrm{Hg}^{2+}$.

$15^{\text {th }}$ Brazilian Meeting on Organic Synthesis - 15 $5^{\text {th }}$ BMOS - November 10-13, 2013 - Campos do Jordão, Brazil

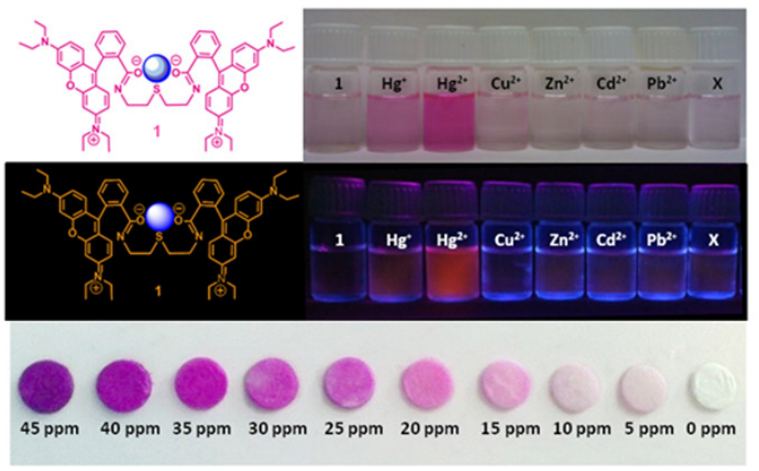

Upper photograph: Colorimetric and fluorescent changes of chemosensor $\mathbf{1}\left(1.00 .10^{-4} \mathrm{M}\right)$ in absolute ethanol in the presence of different metal ions (1 equiv). Only the solution of $\mathbf{1}$ with $\mathrm{Hg}^{2+}$ showed an obvious orange fluorescence.

\section{CONCLUSION}

Two novel probes 1 and 2 containing rhodamine $B$ or rhodamine 640 were synthesized and fully characterized. The low solubility of probes $\mathbf{1}$ and $\mathbf{2}$ in water presents an advantage for the fast and easily detection of $\mathrm{Hg}^{2+}$ in water solution employing an inexpensive and simply cellulose solid support.

\section{ACKNOWLEDGEMENTS}

We are grateful to the Scientific Association ProteoMass (Portugal), C.N. thanks the Xunta de Galicia (Spain) for her postdoctoral contract (I2C program) and to the University of São Paulo through the NAP-CatSinQ (Research Core in Catalysis and Chemical Synthesis) and FAPESP for financial support.

\section{REFERENCES}

${ }^{1}$ Lodeiro, C. et al. Chem. Soc. Rev. 2010, 39, 2948.

${ }^{2}$ Nunez, $\mathrm{C}$ et al. Dyes and Pigments, 2013, in press. 